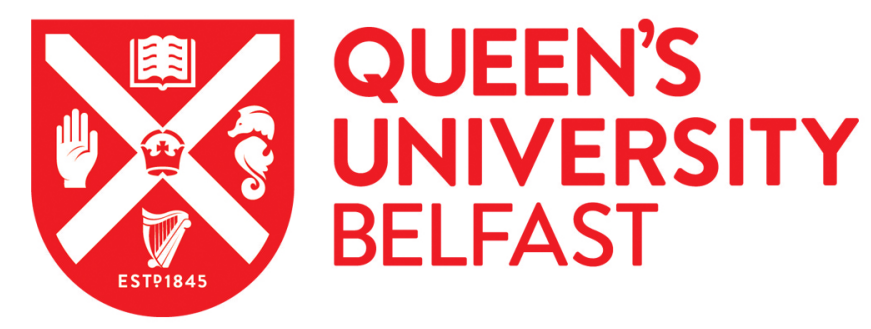

\title{
The challenge to health professionals when carers resist truth telling at the end of life: a qualitative secondary analysis
}

Noble, H., Price, J. E., \& Porter, S. (2015). The challenge to health professionals when carers resist truth telling at the end of life: a qualitative secondary analysis. Journal of Clinical Nursing, 24(7-8), 927-936. [ Journal of Clinical Nursing IF: 1.255 ISI Journal Citation Reports @ Ranking: 2014: 31/109 (Nursing (Social Science))]. https://doi.org/10.1111/jocn.12634

Published in:

Journal of Clinical Nursing

Document Version:

Early version, also known as pre-print

Queen's University Belfast - Research Portal:

Link to publication record in Queen's University Belfast Research Portal

Publisher rights

Copyright 2014 the author(s)

This is the pre-peer reviewed version of the following article: Noble, H, Price, JE \& Porter, S 2014, 'The challenge to health professionals when carers resist truth telling at the end of life: a qualitative secondary analysis' Journal of Clinical Nursing., 10.1111/jocn.12634, which has been published in final form at http://onlinelibrary.wiley.com/doi/10.1111/jocn.12634/abstract

\section{General rights}

Copyright for the publications made accessible via the Queen's University Belfast Research Portal is retained by the author(s) and / or other copyright owners and it is a condition of accessing these publications that users recognise and abide by the legal requirements associated with these rights.

\section{Take down policy}

The Research Portal is Queen's institutional repository that provides access to Queen's research output. Every effort has been made to ensure that content in the Research Portal does not infringe any person's rights, or applicable UK laws. If you discover content in the Research Portal that you believe breaches copyright or violates any law, please contact openaccess@qub.ac.uk. 


\title{
The challenge to health professionals when carers resist truth-telling at the
}

end of life: a qualitative secondary analysis.

\author{
Abstract (294 words) \\ Aims To draw out the similar complexities faced by staff around truth-telling in a \\ children's and adult population, and to interrogate the dilemmas faced by staff when \\ informal carers act to block truth-telling.
}

Background Policy encourages normalisation of death but carers may act to protect or prevent the patient from being told the truth. Little is known about the impact on staff.

Design Secondary analysis of data using a supra analysis design to identify commonality of experiences.

Methods Secondary 'supra analysis' was used to transcend the focus of two primary studies in the UK, which examined staff perspectives in a palliative children's and a palliative adult setting respectively. The analysis examined new theoretical questions relating to the commonality of issues independently derived in each primary study. Both primary studies used focus groups. Existing empirical data were analysed thematically and compared across the studies.

\section{Findings}

Staff reported a hiding of the truth by carers and sustained use of activities aimed at prolonging life. Carers frequently ignored the advance of end of life and divergence between staff and carer approaches to truth-telling challenged professionals. Not being truthful with patients had a deleterious effect on staff, causing anger and feelings of incompetence.

\section{Conclusions}

Both children's and adult specialist palliative care staff found themselves caught in a dilemma, subject to policies that promoted openness in planning for death and informal carers who often prevented them from being truthful to patients about terminal prognosis. This dilemma had adverse psychological effects upon many staff.

\section{Relevance to clinical practice}

There remains a powerful death-denying culture in many societies and carers of dying patients may prevent staff from being truthful with their patients. The current situation is not ideal and open discussion of this problem is the essential first step in finding a solution. 


\section{Key words}

Truth telling

Paediatric

Renal

End of life

Palliative

Qualitative

Staff challenges

Informal carer

\section{Reviewer Key words}

End of life

Nephrology

Children's

Summary box: 'What does this paper contribute to the wider global clinical community?'

1. Truth-telling is a central concern for staff when carers act intentionally or unintentionally to prevent staff being truthful with patients. This paper highlights the detrimental impact on staff when this occurs.

2. The frequent divergence between staff and carer approaches to truth telling appears at the heart of the professional challenge experienced.

3. This paper identifies a convergence of factors in relation to truth-telling including a policy imperative upon palliative care staff to be open with dying 
patients which does not always resonate with lay culture leaving staff in a double-bind which frequently causes them distress.

\section{INTRODUCTION}

Policy in the UK and internationally promotes openness in planning for death (DHSSPS 2010, NHS National End of Life Care Programme. 2012, American Medical Association. 2012, Quality End-of-Life Care Coalition of Canada. 2010). In many Westernised countries there has been a move to normalise death, accept the inevitable and encourage people to plan for the end of life. Although historically, communicating a poor prognosis has been viewed as detrimental to patients' well being, a shift from paternalism towards openness and honesty regarding diagnosis and eventual death has taken place (Fallowfield et al. 2002, Jenkins et al. 2001). This is seen as a way of assisting those with life-limiting disease to make informed choices and openly discuss their impending death and wishes related to care at the end of life (Harrison et al. 2010) in order to promote a 'good death'. However, there is evidence that developments in policy have not been fully reflected in changes in practice. Research has underlined the difficulties facing staff when patients and/or carers deny or refuse to accept 'bad' news (Tuckett 2004, Mahtani-Chugani et al. 2010, de Graaff et al. 2009, de Graaff et al. 2010) However, little is known about the impact on staff when carers act to prevent them being truthful with their dying patients.

\section{BACKGROUND}

Receiving the news that death is approaching is likely to devastate patients and their families (Schaepe 2011) and have wide ranging impact (Harrison et al. 2010, 
Schaepe 2011). Family requests to withhold information are recognised (Hancock et al. 2007) but the move towards increased autonomy has intensified and staff have been supported to develop their communication skills and confidence in order to be able to competently converse openly and honestly about end of life issues (Wilkinson et al. 2008). However, such an approach may be less useful if those affected by impending death do not wish to face or discuss the truth. Although some patients may want to be told the truth about prognosis, there is evidence that others do not (Tuckett 2004, de Graaff et al. 2010, Almack et al. 2012), and carers may collude to protect their loved ones in an effort to maintain hope (Mahtani-Chugani et al. 2010, Spence et al. 2009, Noble et al. 2012). The dilemma regarding patients' refusal to engage in end of life discussions can be solved by clinicians accepting that patient autonomy gives patients the right to decline candid conversations, a right that supersedes the beneficent effects of being informed. However, the issue is far more ambiguous when it is not the patients themselves refusing to engage in end-of-life discussions, but informal carers who serve to prevent such conversations.

While there has been some research exploring staff experience of truth-telling when patients do not want to know, (Mahtani-Chugani et al. 2010, Fallowfield et al. 2002, Hancock et al. 2007), there has been less concentration on the issues raised by the intervention of others. The impact on staff when informal carers act to prevent truthtelling in a climate where policy encourages open engagement with dying patients has rarely been explored. In this secondary qualitative analysis of data from two samples of staff, one caring for children and the other for adults in palliative care settings, we explore how they describe the difficulties of truth telling about terminal prognosis when they are blocked from doing so by carers. 


\section{METHODS}

The aim of qualitative secondary analysis is to re-analyse pre-existing primary data, generate new knowledge and support existing theories. It allows for investigation of new questions (Heaton 2004), maximises the use of existing data (Bernard et al 1986) and prevents research fatigue (Hyman 1972). It involves giving credibility, to events after they have occurred, or to clarify aspects of an event. As noted by Glaser (1962, p.74) qualitative secondary analysis "is not limited to quantitative data" and it is useful for documentary evidence and interviews to be re-analysed.

Our approach represents "supra analysis," which transcends the original focus of a study and involves examining new research questions which may be empirical, theoretical or methodological in nature (Heaton 2004). Heaton (2004) defines supra analysis as qualitative secondary analysis which goes beyond the focus of the original study. In this case, new theoretical questions were derived from extant empirical findings. Using multiple datasets allows for a range of individuals and settings, from which overarching commonalities of experience can be identified (Gladstone et al 2007). In the present study we combined a sub-set of data from two samples of staff caring for populations receiving palliative care and subjected them to re-analysis. The aim was to draw out the similar complexities faced by staff around truth-telling in two terminally ill populations and to interrogate the dilemmas faced by staff when informal carers act to block truth-telling. A more in-depth focus was taken on emergent issues concerned with this aim which were not addressed or only partly addressed by the primary research with the aim of extending the work (Anderson \& Tapash 2013). Thus, a subset of the data from the two research 
studies concerned with complexities faced by staff around truth-telling was examined in more depth.

The first study explored the experiences of health and social care professionals caring for children at the end of life (Price et al 2011, 2012, 2013). The second study explored the experiences and trajectories to death of adults with end stage renal disease (Noble et al 2009; 2010; 2012).

\section{Design}

Secondary analysis of data using a supra analysis design to identify commonality of experiences across two qualitative studies.

\section{Setting and participants}

The first study took place at a regional children's cancer unit and a children's hospice in Northern Ireland. Staff recruited to the study were eligible if they had worked in children's palliative care for over 2 years. Data were collected between November 2008 and January 2009. The study included 35 staff including 24 nurses, 3 doctors, 3 play specialists, 3 health care assistants, 1 teacher and 1 physiotherapist.

The second study took place in a Renal Palliative Care Service at an acute hospital Trust in London. Healthcare professionals were alerted to the study by a poster displayed in clinical areas. Five staff from three other hospitals in the UK (London, Manchester and Leicester) working with patients with advanced CKD managed without dialysis were also recruited to participate. Staff recruited to the study were eligible if they had experience caring for renal patients managed without dialysis. Data were collected between April 2007 to April 2008. Study participants numbered 
24 staff made up of 14 nurses, 8 doctors and two counsellors. Both studies employed purposive sampling (Patton 1990) to capture staff with specific experience of caring for dying children or adults with advanced CKD.

\section{Data Collection}

In the children's study, focus groups $(n=5)$, adopting the nominal group technique (NGT), were used to collect data. The NGT provides a structured process for obtaining qualitative information from target groups associated with a topic of interest (Gallagher et al. 1993, Dewar et al. 2003). A 5-stage process (Scott Sink 1983) was adopted. Issues were discussed in successive rounds of decision-making within an overall process of developing professional consensus (Murphy et al. 1989). A summary review of the major issues identified by parents (Price et al. 2011) was presented to participants (after they had independently generated their own). Both sets of issues (professional and parent) remain independent bodies of data. Focus groups included 6-9 participants, lasted 90-120 minutes and was facilitated by JP.

In the adult study, focus groups $(n=2)$ took place with the local renal multidisciplinary team. Four other focus groups included staff from three other hospitals in the UK. Focus groups were used as semi-structured discussions aimed at exploring specific issues (Liamputtong et al. 2005) related to challenges caring for renal patients as the end of life approached. Comment was invited on the previously analysed patient and carer data generated from the wider study. Although findings from patients and carers were fed back to staff, similar to the children's study the two sets of data remain independent. Focus groups lasted between 50 and 120 minutes and included 5-10 participants. 
Written consent was obtained. The meetings were tape recorded and transcribed with consent from the group. Ethical and research governance approval was granted for both studies (07/NIR02/72 and 06/Q0603/101).

\section{Data Analysis}

Our method of analysis was modelled on that of Heaton's (2004) and Stajduhar et al.'s (2013) approaches to supra analysis. The first step involved assessing the data as appropriate for inclusion in this secondary analysis in that they provided information to address the new research question and were rich in depth and detail. To mitigate the risk that reanalysis might involve misrepresentation of the original findings, one primary dataset was derived from a study led by the first author, and the other from a study led by the second author, thus ensuring thorough familiarity with the original research projects. Transcripts were combined manually within Microsoft word (Hahn 2008) using the comments feature which allows codes to be attached to meaning units in a transcript and the 'find feature' which identifies specific codes. The original interview transcripts were read and re read to ensure familiarisation of the data. The authors met several times to share early interpretations Data related to the aim of the present study were identified and summaries of the relevant content within each interview captured. This helped inform the development of codes related to truth telling. A data base was collated and comments related to the interviews and centred on complexities faced by staff around truth-telling at the end of life were maintained. This master data base helped in the interpretation and refining of the data in order to construct themes. HN and JP undertook the final interpretation of the data set which was discussed with SP until consensus was reached. 


\section{FINDINGS}

In both studies, truth-telling emerged as a central concern for professionals. Crossstudy analysis identified similar themes in both studies: 'Hiding of the truth', 'Practical consequences of not dealing with the truth' and 'Professionals' response when unable to be truthful'.

\section{Hiding of the truth}

Frequent divergence between staff and parent approaches to truth telling appeared at the heart of the professional challenge experienced. In the children's study, the problems surrounding truth-telling were exacerbated by the complexities inherent in communicating with children (including siblings) about death in the face of parents who refused to admit to their child that they were dying.

'There's a family their son is dead 2 years ....he died at 18, they never ever discussed dying with him. He discussed with others at teenage weekends though...one weekend he asked. He was protecting the parents. (FG3-C)* ${ }^{\star} F G=$ Focus Group followed by number of group $C=$ children's study

Staff reported parents undertaking a complex game of 'hiding the truth' of impending death in an effort to protect their child from potential further suffering. Ironically, children sometimes played the same game simultaneously in order to protect their parents.

Contrary to the belief of many parents, staff were often convinced that the most appropriate strategy was to be open and honest with the child. Staff believed 
children frequently possessed a much deeper understanding about death than their parents appreciated and if children were kept informed this might aid in alleviating potential worries about dying.

'It is the honesty about what to say to the families who may not have accepted their child is going to die and the child doesn't know. ...you say to the family you have to tell the child ... because children want to know'.(FG3-C)

The dilemma for staff became more acute when older children were involved:

I find it quite difficult whenever the patient is a child near adolescence and doesn't know, well you know they know but the parents don't tell them everything (FG4-C)

In the adult study, staff reported carers protecting loved ones by choosing not to dwell on the end of life, preferring instead to live in hope.

I don't know, it was just something that I came across and then had relatives saying, well we don't talk about it (dying). They just didn't engage in it for whatever reason (FG3-A)

$A=$ adult study

They reluctantly colluded with this pretence, acknowledging there was little else they could do. This lack of acceptance was sometimes linked to optimism generated from the fact that the child or adult may have made a recovery in the past when the prognosis had been extremely poor. These 'repeated returns from the brink' led to some carers living in hope that recovery might occur again. In contrast, staff regarded these cycles of partial recovery and further decline as downward spirals 
rather than indications of possible recovery. They felt that carers' hopes were an obstacle to accepting the inevitable and subsequently talking about the truth:

The more recoveries they make, makes it more difficult (FG2-C)

In the children's study, if staff attempted to discuss a poor prognosis with the parents and the child subsequently improved physically, the relationship between the staff member and parent sometimes suffered, with the parent resenting the staff member for suggesting their child might be close to death:

If someone says something to family, the end is near and the child picks up. The family can take a dislike to this person. Families listen to and hang on to every word (FG3-C)

Staff reported some carers as being unable to face the fact that death was approaching.

Yes, I know families who say, 'don't say anything, because we haven't said anything. We are keeping a happy face on things' (FG3-A)

This left staff feeling helpless and unable to be honest. In addition, staff spoke of 'blocks' put in their path which left them understanding in no uncertain terms that the truth was not to be discussed:

Practical consequences of avoiding the truth. 
The practical consequences of avoiding the truth led to further difficulties for staff. For example, feeding was identified as particularly problematic. Withdrawal of food was acknowledged as a profoundly distressing decision for parents, given the centrality of food and feeding to their sense of themselves as adequately nurturing their child and the implications that such withdrawal carried in terms of hastening death. Staff reported parents attempting to feed children in impossible circumstances:

Parents were in denial ... wanting to feed their child even when the child wasn't swallowing (FG3-C)

Consequently, having to initiate and talk through the issue of withdrawal of feeding was considered extremely stressful by staff. Similar intentions were seen in the adult study where carers worried about poor nutritional intake and providing nourishing food.

So I had to say to her I think he's dying, ... he's going to die very soon ... but they just continued focussing on making the patient eat ... like that was their key priority (FG1-A)

The same phenomenon was identified by participants in relation to withdrawal of treatment. Even when accepted by carers that death was close, they sometimes engaged in actions that were not consonant with this acceptance, such as encouraging admission to hospital: 
This family allowed their father to go in to hospital ... they knew he was dying because they asked how much longer and I've had long conversations with them, but they were delighted that he'd been brought in that he had some fluids. And the palliative care doctor said I thought I was going to find this irate family ... but they were delighted (FG2-A)

Inappropriate interventions for adult patients, including surgery or resuscitation were reported. Although these interventions were prompted by healthcare practitioners, the carers' failure to challenge such actions perhaps reflected death-denial even when it had been made clear the patient was dying. One respondent recounted the experience of a patient offered surgery for an acute abdomen at the end phase of life without any resistance from his carers.

Another area of contention in both populations concerned the administration by carers of complementary therapies.

They read about them (herbal remedies) on the internet, how fabulous they are and they're $100 \%$ this is going to work and the child's getting sicker and sicker (FG1-C)

Staff often viewed these interventions as futile and a pretext for avoiding the inevitability of death.

We were discussing the herbal medicines. I asked her (daughter) what's going to happen when father becomes unwell ... she said I just need to get him home and he wont die (FG3-A) 
In this last quote a daughter regularly gave her father a herbal remedy which she felt was prolonging his life although he eventually deteriorated and died.

\section{Professionals' response when unable to be truthful}

Whilst professionals in both studies felt they continuously strove to provide quality palliative care, they felt frustration at their inability to provide adequate end of life care.

You can't do the things you feel are needed [for the patient ] and I feel helpless and unsure and just want to 'get it right' (FG1-A)

Although participants gained considerable fulfilment from their work, emotional impact was most frequently discussed in negative terms. This included strong feelings of inadequacy, dissatisfaction and sadness arising from the complex, intense and often protracted nature of professional engagement with the dying and wider family when truth-telling appeared prevented.

'Dealing with your own personal feelings of sadness - there would be something wrong if you're able to go through this and not feel moved.'(FG4-C)

This situation caused consternation and worry to staff that they might not be acting in patients' best interests, particularly in the period when patients deteriorated. As shown in the next quote, staff might attempt to persuade carers to accept a deterioration in a patient's condition towards death so that access could be made to supportive services. Often carers would not accept this and access was therefore denied. 
Anyway, I rang the wife and I said, "The GP asked whether you would like your husband referred to the hospice? Are you managing at home, is there anything more that you need? She said, "Oh, he is quite well at the moment", and la, la, la, and then two weeks later, he died! You think, I suppose I should have just referred him anyway, but then they weren't ready at that point. Did I do the right thing? (FG2A)

Staff working in the children's setting staff frequently became fearful when left alone caring for a child, in case the child posed a question directly to staff concerning prognosis that they felt unable to answer.

One of the big ones for me ...is if parents say to you don't tell them they're dying and no matter how experienced you are, if a child turns round to you and says 'Am I dying?', what do you do, it's very, very difficult and it's how to manage that... (FG2-C)

This disparity between professional and parental opinions often gave rise to underlying tension, resulting in parental anger and leading to additional stress for staff.

Parents often have an inability to accept what they've been told and therefore the anger you've then got to deal with ... and some people's conflict between medicine and reality. Parents always want more (input) (FG3-C). 
A particular problem for staff in the adult setting related to the paucity of prognostic evidence concerning patients with non-dialysed end-stage kidney failure. Supportive and palliative care for this population is a relatively new concept. Much knowledge is limited to anecdote or experience.

Why did you go in and see that patient and think and do as you do? It is still all completely up in the air, isn't it? We are all working out clinically through clinical experience, what our feeling is about the patient and what their needs are but it is not evidence-based and we don't know the best things to do (FG2-A).

This limited staff's ability to be truthful and honest with patients as uncertainty around how people might progress to death and the possibility of incorrect prognosis led to a questioning of personal competence:

In thinking about how the challenge of communication in the face of carers resistant to engagement with the truth, staff felt little could be done.

No matter how much training you have it is always difficult. There will always be times you think you will do wrong (FG2-C).

Even if appropriate training had been received, the challenge appeared insurmountable to them causing further dissatisfaction:

\section{DISCUSSION}

Palliative care patients are not a homogenous group. The experience of care during the dying phase will be significantly different for different individuals and groups of patients. However, while it is important to identify specificities, it is also important to recognise that there are commonalities that cross very different patient groups. The 
secondary analysis presented here illustrates the impact carers of patients may have on the communication process between staff and patient. Barriers to truth-telling arose in both studies, and commonality of experience of palliative care specialists across specialties and age groups was seen. Reflecting the findings of previous studies (Small et al. 2009, Seale 1998, Calvin 2004, Hammoud et al. 2005, Boyd et al. 2004, Zhang et al. 2003, Miller et al 2013), informal carers were often reluctant to discuss death and dying. In attempting to protect their dying loved ones, they acted as barriers by preventing staff being truthful with the patient they were caring for. Even where professionals felt sure that telling the truth was the most appropriate form of action, they felt powerless. The distress that this caused, coupled with uncertainty concerning the timing of death, intensified problematic communication between carers and professionals. Avoidance of the truth may involve a 'mutual pretence'. Mutual pretence, originally identified by Glaser \& Strauss (1965) with adults and later confirmed in dying children (Bluebond-Langner 1978), is the situation where both patient and carers know death is imminent, and each endeavour to protect the other by not revealing this truth. Consequently, a complex process of protection between parents/children/adults ensues, where the dying person remains silent in an attempt to protect loved ones who do likewise to protect the dying. It might be thought that while mutual pretence and truth avoidance is a common phenomenon affecting both parents of dying children and adults caring for dying adults, the fundamental difference in these relationships, one of which is adult / adult, the other adult / child, requires a different approach by palliative care staff. However, such an assumption is based on a paternalistic view of children's rights, a view not reflected in current policy. A child's capacity to take part in treatment decisions is centred on a moral and ethical requirement to respect the rights and 
autonomy of every individual, regardless of age. Although it is expected that children and adolescents will be involved in decision-making, end-of-life decision-making has been identified as particularly complex (Canadian Paediatric Society. 2004). Parents may find it easier to assume that their child will not understand and therefore avoid the subject in order to reduce fear and potential anxiety (Price et al. 2009). Conflict may arise if staff attempt to protect the rights and autonomy of the child versus those of the parents (Feudtner 2007). The key principles underpinning children's palliative care practice stress the importance of autonomy and self-determination for the child balanced by the duty of beneficence which requires consideration of the best interests of the child (Beauchamp et al. 2001).

Similarly, in the adult population, health care professionals are taught to uphold the autonomy and self-determination of patients, respect their dignity and human rights and act in their best interests (Beauchamp \& Childress, 2001). That said, vulnerable older adults are considered at high risk of losing their autonomy. Family members may make decisions on behalf of a capable parent, or there may be a lack of awareness of the normal changes that occur in older age that make an older adult appear less competent than they are. Complicating this issue are questions concerning the ability of older adults to act competently and to have capacity (Naik, Lai, et al. 2008). There are a variety of dimensions to capacity, including the ability to make decisions, carry out personal care and to self-protect. The ability to complete these roles can fluctuate, particularly at times of ill health, making the older adult vulnerable to having others decide their best interests. 
Open discussion about death with children, particularly those approaching death, has been identified as particularly challenging for professionals (Papadatou et al. 2001, Papadatou et al. 2002, Contro et al. 2004) as well as parents (Jones 2006, Theunissen et al. 2007). Although research has established the benefits of open discussion with dying children (Graham-Pole et al. 1989), parents may assume their child will fail to understand the issues surrounding death. The data presented here demonstrate parents' reluctance to broach the subject in an attempt to 'protect' their child, a reluctance with which staff felt obliged to collude, despite their professional obligations. Palliative care staff found themselves caught in a double bind in which an acceptable response to one obligation entailed a failure to successfully respond to the other (Bateson 1972). This sometimes led to moral distress, the harmful psychological result of believing that a certain course of action is the correct one to take, while simultaneously feeling constrained from taking it (Jameton 1984).

This study has identified an unfortunate convergence of factors in relation to truthtelling. First, there is a policy imperative upon palliative care staff to be open with patients about prognosis in order to allow them to face their end in an autonomous and dignified fashion. Second, these policy imperatives did not always resonate with lay culture. Third, these contradictory influences left staff in a double-bind which frequently caused them distress.

\section{Limitations of the study}

This paper reports two studies in two areas of the UK and the findings may not apply similarly across all populations. Ethical and research governance approval was 
granted for both original studies. It was not possible to contact participants for their agreement to secondary analysis of data but the study was carried out in accordance to the Declaration of Helsinki (World Medical Association, 2008) and participants were not identified. It is acknowledged that data were not collected to specifically inform a new research question and the data presented are based on the views of staff only. Methodological limitations also exist in that the findings cannot be validated with the original research participants. That said secondary analysis can assist in making best use of data from hard to reach groups such as those who are dying.

Another potential limitation concerns the possibility that the original data were distorted in the process of secondary analysis. However, careful use of the supra analysis design, combined with the authors' intimate knowledge of the primary studies helped ensure that the resultant analysis remained true to the principles of the original research

\section{CONCLUSION}

This secondary analysis of two qualitative datasets indicates a variety of ways in which palliative care staff found themselves caught in an impossible dilemma. Policy both in the UK and internationally promotes openness in planning for death but there remains a powerful death-denying culture in many societies, including the UK, and carers of dying patients sometimes prevented staff from being truthful with their patients. Because of the detrimental effects upon specialist palliative care staff, the current situation is far from ideal. However, rather than presuming to assert a solution, we hope instead that this paper will encourage debate about how best to 
deal with the problem. Our reluctance to propose a definitive line of action lies in the fact that there are significant drawbacks with any of the potential directions that could be taken. However, we are convinced that open discussion of this problem is the essential first step in finding a solution.

\section{IMPLICATIONS FOR PRACTICE}

We have identified three alternative approaches that could be taken in response to the dilemma presented in this paper. The first is to reinforce policy recommendations concerning openness of communication so that the imperative upon staff to be candid is stronger, leaving less room for them to acquiesce to the pressure from carers to dissimulate. In this way, policy could be used as a more proactive tool to change culture. However such an approach would almost certainly lead to a considerable exacerbation of conflict between staff and carers, thus increasing rather than decreasing the likelihood of moral distress. One only needs to look at the moral panic stirred up in the UK in response to the Liverpool Care Pathway for the Dying (BMJ 2013) to appreciate the risks of such a strategy.

The second option is to accept cultural mores as determinant of practice and to redesign policies so that they no longer equate insight and autonomy with the 'good death'. This might have the effect of solving the double bind by releasing staff from the obligation to seek to enlighten dying patients as to their prognosis, but it defies the evidence that palliative care patients who are afforded information about their condition in a sensitive way tend to benefit psychologically from that information (Hancock et al. 2007). 
The final alternative is maintenance of the status quo, and an expectation that staff implement aspirational policies, using their own discretion to deal with situations where their views of the best approach to truth-telling differ from that of informal carers of a dying patient. Given the substance of this paper, there is no need to rehearse here the problems that this alternative entails.

One possible route forward is to reemphasise the core ethical concept of patient autonomy where staff are clear that if they are asked questions by patients, they have an ethical and policy-derived obligation to answer them without lying. While such an approach would have little effect upon staffs' ability to proactively initiate end of life conversations, it would at least relieve them of the moral distress of having to lie, and more importantly, it would provide patients with a route to find out the truth if they wished to know it, independently of the wishes of their informal carers.

\section{Authors' contributions}

$\mathrm{HN}$ and JP participated in the design of the primary studies, data collection and performed the qualitative analysis. SP made substantial contributions to the secondary interpretation of data. HN drafted the manuscript, assisted by JP and SP. All authors approved the final manuscript. 


\section{REFERENCES}

Almack, K., Cox, K., Moghaddam, N., Pollock, K. \& Seymour, J. (2012) After you: conversations between patients and healthcare professionals in planning for end of life care, BMC Palliative Care, vol. 11, no. 1, pp. 15.

American Medical Association (2012) AMA policy on end of life care, http://www.ama-assn.org/ama/pub/physician-resources/medical-ethics/aboutethics-group/ethics-resource-center/end-of-life-care/ama-policy-end-of-lifecare.page [12/12/13].

Anderson, C \& Tapash R (2013) Patient experiences of taking antidepressants for depression: A secondary qualitative analysis. Research in Social and Administrative Pharmacy 9: 884-902

Bateson, G. (1972) Double bind 1969. Steps to an ecology of the mind: A revolutionary approach to man's understanding of himself., University of Chicago Press, Chicago.

Beauchamp, T. \& Childress, J. (2001) Principles of biomedical ethics, 5th edn, Oxford University Press, Oxford.

Bernard HK, Pelto P, Werner O, et al. (1986) The construction of primary data in cultural anthropology. Current Anthropology;27: 382-396.

Bluebond-Langner, M. (1978) The Private worlds of dying children. University Press, Princeton.

BMJ (2013) Bad press over Liverpool Care Pathway has scared patients and doctors, say experts. Available: http://www.bmj.com/content/346/bmj.f175 [12.12.13].

Boyd, K., Murray, S.A., Kendall, M., Worth, A., Benton, T.F. \& Clausen, H. (2004)"Living with advanced heart failure: a prospective, community based study of patients and their carers", The European Journal of Heart Failure, vol. 6, pp. 585-591.

Calvin, A. (2004)"Haemodialysis patients and end-of-life decisions: a theory of personal preservation", Journal of advanced nursing, vol. 46, no. 5, pp. 558-566.

Canadian Paediatric Society. (2004)" Treatment decisions regarding infants, children and adolescents", Paediatric Child Health, vol. 9, no. 2, pp. 99-103.

Contro, N., Larson, J., Schofield, S., Sourkes, B. \& Cohen, H. (2004)"Hospital staff and family perspectives regarding quality of pediatric palliative care. ", Pediatrics, vol. 14, no. 5, pp. 1248-1252.

de Graaff, F. \& Francke, A.L. (2009)"Barriers to home care for terminally ill Turkish and Moroccan migrants, perceived by GPs and nurses: a survey", BMC Palliative Care, vol. 8, pp. 3.

de Graaff, F., Francke, A.L, van, D.M. \& van, D.G. (2010)"'Palliative care': a contradiction in terms? A qualitative study of cancer patients with a Turkish or Moroccan background, their relatives and care providers", BMC Palliative Care, vol. 9, no. 1, pp. 19.

DHSSPS (2010) - Living Matters: Dying Matters. A Palliative and End of Life Care Strategy for Adults in Northern Ireland, 2010. Available: www.endoflifecareforadults.nhs.uk/publications/living-matters-dying-matters-apalliative-and-end-of-life-care-strategy-for-adults-in-northern-ireland [12.12.13].

Dewar, A., White, M., Santiago, T., Posade, M. \& Dillon, W. (2003)"Using Nominal Group Technique to assess chronic pain, patients' perceived challenges and needs in a community health region", Health Expectations, vol. 6, pp. 44-52. 
Fallowfield, L.J., Jenkins, V.A. \& Beveridge, H.A. (2002)_"Truth may hurt but deceit hurts more: communication in palliative care", Palliative medicine, vol. 16, no. 4, pp. 297-303.

Feudtner, C. (2007)"Collaborative communication in pediatric palliative care: A foundation for problem-solving and decision-making", Pediatric Clinics of North America., vol. 54, no. 5, pp. 583-607.

Gallagher, M., Hares, T., Spencer, J., Bradshaw, C., .Webb, I. (1993)"The Nominal Group Technique: A research tool for general practice.", Family Practice, vol. 10, no. 1 , pp. 76-81.

Gladstone BM, Volpe T and Boydell KM. (2007) Issues encountered in a qualitative secondary analysis of help-seeking in the prodrome to psychosis. Journal of Behavioural Health Service Research. vol 34 (4):431-442.

Glaser, B. \& and Strauss, A. (1965), Awareness of dying, Aldine Publishing Co, Chicago.

Glaser, B. G. (1962)- Secondary Analysis: A Strategy for the Use of Knowledge from Research Elsewhere. Social Problems, vol 10(1) : 70-74

Graham-Pole, J., Wass, H., Eyberg, S. \& and Chu, L. (1989)_"Communication with dying children and their siblings: A retrospective analysis", Death Studies, vol. 13, pp. 1-16.

Hahn C (2008) Doing Qualitative Research Using Your Computer: A Practical Guide. Sage, London

Hammoud, M., White, C. \& Fetters, M. (2005)_"Opening cultural doors: Providing culturally sensitive healthcare to Arab American and American Muslim patients. [Editorial]", American Journal of Obstetrics \& Gynecology, vol 193 (4) 13071311.

Hancock, K., Clayton, J.M., Parker, S.M., Der Wal, S., Butow, P.N., Carrick, S., Currow, D., Ghersi, D., Glare, P., Hargerty, R. \& Tattersall, M. (2007) "Truth telling in discussing prognosis in advanced life-limiting illnesses: a systematic review", Palliative Medicine , vol 21 507-517.

Harrison, M.E. \& Walling, A. (2010)_"What Do We Know About Giving Bad News? A Review", Clinical pediatrics, vol 49 (7):619-26

Heaton J. (2004) Reworking qualitative data. London: SAGE

Hyman HH. (1972) Secondary analysis of sample surveys: principles, procedures and potentialities. New York: John Wiley \&Sons.

Jameton, A. 1984(1984); Nursing practice: The ethical issues, NJ: Prentice-Hall, Englewood Cliffs. Jenkins, V., Fallowfield, L. \& Saul, J. (2001)"Information needs of patients with cancer: results from a large study in UK cancer centres", British journal of cancer, vol 84 (1) pp. 48-51.

Jones, B. (2006)_"Companionship, Control, and Compassion: A Social Work Perspective on the Needs of Children with Cancer and their Families at the Endof-life", Journal of Palliative Medicine, vol. 9, no. 3, pp. 774-788. 
Kreicbergs, U., Valdimarsdottir, U., Onelov, E., Bjork, O., Steineck, G. \& and Henter, J. (2005) "Care related distress: a nationwide study of parents who lost their child to cancer.-", Journal of Clinical Oncology, vol. 23, no. 36, pp. 9152-9171.

Liamputtong, P. \& Ezzy, D. (2005); Qualitative Research Methods 2nd edn, Oxford University Press, Melbourne, Victoria.

Mahtani-Chugani, V., González-Castro, I., Sáenz de Ormijana-Hernández, A., Martín-Fernández, R. \& and Fernández de la Vega, E (2010)_"How to provide care for patients suffering from terminal non-oncological diseases: barriers to a palliative care approach-", Palliative Medicine, vol. 24, pp. 787-791.

Millar, C., Reid, J. and Porter, S. (2013) Refractory cachexia and truth-telling about terminal prognosis: a qualitative study. European Journal of Cancer Care, vol vol 22(3), 326-333.

Murphy, M., Black, N., Lamping, D. \& et al (1989) "Consensus Development methods and their use in clinical guidelines development. Health Technology Assessment vol. 2, no. 3, pp. 1.-88.

Naik, A. D., Burnett, J., Pickens-Pace, S., \& Dyer, C. B. (2008)- Impairment in instrumental activities of daily living and the geriatric syndrome of self-neglect. The Gerontologist, vol 48(3), 388-393.

NHS National End of Life Care Programme (2012) Critical success factors that enable individuals to die in their preferred place of death. .http://www.endoflifecare.nhs.uk/assets/downloads/EoLC_CSF_Report_for_Publ ication_2.pdf [12.12.13].

Noble, H., Kelly, D. \& Hudson, P. (2012)."Experiences of carers supporting dying renal patients, managed without dialysis", Journal of Advanced Nursing, Nov 20. doi: 10.1111/jan.12049. Nov 20. doi: 10.1111/jan.12049. [Epub ahead of print]

Noble, H., Meyer, P.J., Bridge, D.J., Johnson, D.B. \& Kelly, D.D. (2010)."Exploring symptoms in patients managed without dialysis: a qualitative research study", Journal of renal care, vol. 36, no. 1, pp. 9-15.

Noble, H., Meyer, J., Kelly, D., Johnson, B. \& Bridges, J. (2009)."Reasons renal patients give for deciding not to dialyse: prospective qualitative interview study", Dialysis \& Transplantation, vol. 38, no. 3, pp. 82-89.

Papadatou, D., Bellali, T., Papazoglou, I. \& and Petraki, D. (2002)_"Greek nurse and physician grief as a result of caring for children dying of cancer", Pedaitric Nursing, vol. 28, no. 4, pp. 345-365.

Papadatou, D., Martinson, M. \& Man Chung, P. (2001)_"Caring for dying children: A comparative study of nurses' experiences in Greece and Hong Kong.", Cancer Nursing, vol. 24, no. 5, pp. 402-412.

Patton, M. (1990)-, Qualitative evaluation and research methods, 2nd edn edn, Sage, Newbury Park.

Price, J. \& McNeilly, P. (eds) (2009), Palliative Care for Children and Families - An Interdisciplinary Approach, Palgrave Macmillan, UK.

Price, J., Jordan, J., Prior, L. \& Parkes, J. (2011)_"Living through the death of a child: A qualitative study of bereaved parents' experiences", International Journal of Nursing Studies, vol. 48, no. 11, pp. 1384-1392.

Price, J., Jordan, J., Prior, L. \& Parkes, J. (2012)_"Comparing the needs of families of children dying from malignant and non-malignant disease: an in-depth qualitative study", BMJ Supportive \& Palliative Care, 2:127-132.

Quality End-of-Life Care Coalition of Canada- (2010); Blueprint for action 2010-2012, Quality End-of-Life Care Coalition of Canada, Canada. 
Schaepe, K.S. (2011)."Bad news and first impressions: Patient and family caregiver accounts of learning the cancer diagnosis", Social science \& medicine, vol. 73, no. 6 , pp. $912-921$.

Scott Sink, D. (1983)_"Using the Nominal Group Technique Effectively", National Productivity Review, pp. 173-184.

Seale, C. (1998)_"Theories in health care and research: Theories and studying the care of dying people", BMJ, vol. 317, no. 7171, pp. 1518-1520.

Small, N., Barnes, S., Gott, M., Payne, S., Parker, C., Seamark, D. \& Gariballa, S. (2009)_."Dying, death and bereavement: a qualitative study of the views of carers of people with heart failure in the UK", BMC Palliative Care, vol. 8, no. 1, pp. 6.

Spence, A., Hasson, F., Waldron, M., Kernohan, W., McLaughlin, D., Watson, B. \& et al. Professionals delivering (2009)."Professionals delivering palliative care to people with COPD: qualitative study", Palliative Medicine. vol 17(4):359-67

Stajduhar, K., Funk, L. \& Outcalt, L. (2013) Family caregiver learning: how family caregivers learn to provide care at the end of life: a qualitative secondary analysis of four datasets. Palliative Medicine, 27(7), 657-664.

The Gold Standards Framework (2012)-, Enabling a gold standard of care for all people nearing the end of life. Available: http://www.goldstandardsframework.org.uk/ [12.12.13].

Theunissen, J., Hoogerbrugge, P.M., van Acterberg, T. \& et al (2007). "Symptoms in the palliative phase of children with cancer", Pediatric Blood Cancer, vol. 49, pp. 160-165.

Tuckett, A.G. (2004)_"Truth-Telling in Clinical Practice and the Arguments for and Against: a review of the literature", Nursing ethics, vol. 11, no. 5, pp. 500-513.

Wilkinson, S., Perry, R., Blanchard, K. \& Linsell, L. (2008)."Effectiveness of a threeday communication skills course in changing nurses' communication skills with cancer/palliative care patients: a randomised controlled trial", Palliative Medicine, vol. 22, no. 4, pp. 365-75.

World Medical Association (2008) Declaration of Helsinki - Ethical Principles for Medical Research Involving Human Subjects

http://www.wma.net/en/30publications/10policies/b3/ (12.12.13)

Zhang, A.Y. \& Siminoff, L.A. (2003)"Silence and Cancer: Why Do Families and Patients Fail To Communicate?", Health communication, vol. 15, no. 4, pp. 415429. 